\title{
Cmambu
}

\section{ЗАКОНОМЕРНОСТИ ИЗМЕНЕНИЯ МОТИВАЦИИ ПРОФЕССИОНАЛЬНОЙ ДЕЯТЕЛЬНОСТИ ПЕДАГОГОВ}

\author{
А.В. ГОРБУШИНА, Г.И. КОРЧАГИНА \\ а ФГБОУ ВО «Вятский государственньй университет», 610000, Россия, г. Киров, ул. Московская, \\ d. 36
}

\begin{abstract}
Резюме
Актуальность исследования заключается в расширении научных представлений о генезисе и закономерностях изменения мотивации профессиональной деятельности педагогов, а также в решении практических задач поддержки педагогической деятельности за счет актуализации ресурсов мотивации учителей. Цель статьи - описание генезиса и темпоральных закономерностей изменения мотивации профессиональной педагогической деятельности на материале эмпирического исследования динамики структуры мотивации деятельности учителей с разным трудовым стажем. Методологическую основу исследования составили системогенетический и метасистемный подходы. Ведущие методы исследования - метод анализа психологической структуры и метод моделирования. В результате их применения путем сопоставления системогенетических закономерностей с изменениями в структурно-уровневой организации мотивации деятельности учителей были определены генезис и принципы трансформации мотивации профессиональной педагогической деятельности во временно́м континууме. В статье раскрыты предикторы формирования и закономерности динамики субсистемного и компонентного уровней в структуре мотивации профессиональной педагогической деятельности. Показано, что на первых этапах динамики изменения ключевых уровней структуры осуществляются по принципам системогенеза: иерархии, целевой детерминации, неравномерности, дифференциации и др. После преодоления системой кризиса изменения осуществляются по принципам метасистемогенеза: гетерархии, гетерохронности, ситуационной детерминации, цикличности и др. Выявление темпоральных закономерностей изменений структуры мотивации деятельности учителей показывает нелинейный характер трансформации и непрерывность развития мотивации в системе профессиональной педагогической деятельности. Полученные данные могут быть использованы специалистами для проектирования систем актуализации мотивации и поддержки профессиональной деятельности учителей.
\end{abstract}

Ключевые слова: концептуальная модель мотивации профессиональной педагогической деятельности, генезис, закономерности изменений, системогенез, принципы метасистемогенеза.

\section{Введение}

Изучение мотивации профессиональной деятельности педагогов является предметом многих научных исследований. За последнее десятилетие в данной 
области накоплен обширный эмпирический материал: исследованы отдельные мотивы, типы мотивации педагогической деятельности (Марук, Правдина, 2015; Кожевина, Дубровина, 2018), взаимосвязь мотивации с эмоциональным выгоранием (Метеличев, Шингаев, 2014; Рокицкая, 2017), взаимосвязь мотивации с действием организационных факторов (Fernet, 2016; Kamalova et al., 2016; Mintrop, Ordenes, 2017; Viseu et. al, 2016), описаны отдельные изменения в соотношении внутренней и внешней мотивации учителей в зависимости от педагогического стажа (Львова, 2015). Имеющиеся в науке данные относительно мотивации профессиональной педагогической деятельности (далее - МППд) определяют предпосылки дальнейшего более глубокого исследования - определения генезиса, структуры, характеристики происходящих в ней изменений.

Концептуализация предметной области, создание модели мотивации профессиональной деятельности и ее экспликация в контекст педагогической деятельности позволяют реализовать собственно системное исследование МППД и создать многомерное представление о предметной области: не только о структуре МППД, ее функционировании и изменении во временно́м континууме, но и о закономерностях происходящих трансформаций. Полученные результаты могут стать основой для проектирования системы мер поддержки педагогов в современных школах в условиях интенсификации образовательной среды и повышения качества образования за счет актуализации резервов профессиональной мотивации.

Целью данной статьи является описание генезиса и темпоральных закономерностей изменения МППД на материале эмпирического исследования динамики структуры мотивации деятельности учителей с разным трудовым стажем.

\section{Методология и методы}

\section{Методологические принципы организащии исследования}

Отправной методологической точкой при организации исследования стали положения системного подхода (Ломов, 1984). В качестве базового методологического подхода к изучению генезиса и закономерностей изменений МППД выступил системогенетический подход (Шадриков, 2013, 2017), развитие его идей в методологии метасистемогенеза (Карпов, 2004, 2015), а также логика их применения к изучению мотивации учебной (Карпова, 2009) и научной деятельности (Разина, 2016). Системогенетический подход позволяет описать МППД как функциональную систему, развивающуюся с течением времени и имеющую вариативное содержание. Метасистемный подход дает возможность охарактеризовать взаимодействие системы МППд с более крупными метасистемами личности и профессиональной деятельности, в которые она онтологически включена, а также объяснить возможности управления нижележащего по функциональной направленности и генезису образования (МППД) более крупными и глобальными метасистемами - личности и профессиональной деятельности. 


\section{Модель структурно-уровневой организачии МППД}

На основе работ В. Д. Шадрикова $(2013,2017)$, А. В. Карпова $(2004,2015)$, Е. В. Карповой (2009), Т. В. Разиной (2016) была разработана концептуальная модель структуры МППД и ее экспликация в структуру психологической системы профессиональной деятельности (рисунок 1).

Под МППД мы понимаем динамическую функциональную систему, имеющую структурно-уровневую организацию детерминант, побуждающих к осуществлению педагогической деятельности на нормативно требуемом уровне, формирующуюся в мотивационной сфере личности при условии включения в особую ситуацию профессионального социального взаимодействия и самостоятельного выполнения педагогической деятельности и развивающуюся с течением времени.

Система МППД относится к особому классу систем со встроенным метасистемным уровнем (Карпов, 2015; Карпова, 2009; Разина, 2016). В более ранних работах мы описывали структуру МППД подробно (Горбушина, 2011). На рисунке 1 представлена структурно-уровневая организация МППД в виде иерархически упорядоченных уровней, среди которых основные функцио-

Рисунок 1

Экспликация структуры мотивации профессиональной педагогической деятельности в мультиплицированную структуру системы педагогической деятельности

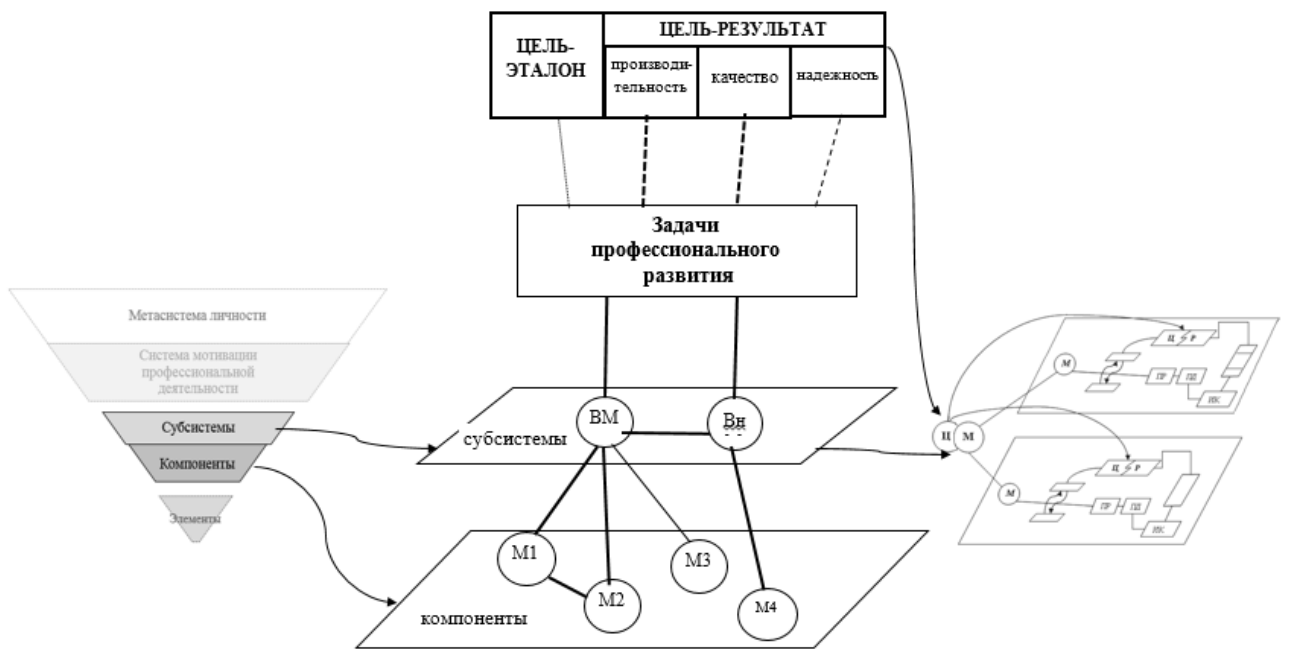

Примечание. М1, M2, M3, M4 - личностные диспозиции, выступающие в функции мотива, ВМ - внутренняя мотивация, Вн - внешняя мотивация, Ц - цель педагогической деятельности, М - мотивация педагогической деятельности, $\mathrm{P}$ - результат, ПР - принятие решения, ПД - программа деятельности, ИК - контроль. 
нальные проявления МППД обеспечивают компонентный и субсистемный уровни (Карпов, 2004, 2015; Карпова, 2009; Разина, 2016). Различные личностные диспозиции, проявляющиеся в своей мотивационной функции, объединяясь между собой, образуют функциональные субсистемы, имеющие качественное своеобразие и выступающие проявлением МППД как системы в целом. Преломляясь через задачи профессионального развития, стоящие перед учителем на разных этапах профессионализации, мотивационные образования по-разному будут обеспечивать достижение целей педагогической деятельности и их отдельных критериев. Особое сочетание функциональных блоков мотивации и цели деятельности, образующее вектор «мотив - цель» (Шадриков, 2013, 2017), будет во многом определять содержание педагогической деятельности. Другими словами, особенности структуры мотивации на разных временны́х отрезках по-разному отражаются на содержании деятельности учителя. По этой причине реализация структурно-уровневого плана системного изучения (Карпов, 2015) МППД является методологически исходной точкой для исследования генеза и закономерностей изменений системы мотивации профессиональной деятельности педагогов в целом.

\section{Методы и методический инструментарий}

Для реализации генетического плана изучения МППД был использован синтез метода анализа психологической структуры и метода моделирования, позволяющий на основе особенностей структурно-уровневой организации мотивации деятельности учителей с разным трудовым стажем путем сопоставления с принципами системогенеза выявить темпоральные закономерности изменений в системе МППД.

Батарею психодиагностических методик составили: опросники «Словарь» И.Г. Кокуриной (1984), «Мотивация работой» И.П. Пономарева (2004), «Структура мотивации трудовой деятельности» К. Замфир в адаптации А.А. Реана (1999). С их помощью были собраны сведения о компонентах (мотивах) и функциональных субсистемах профессиональной мотивации респондентов.

\section{База исследования и этапы анализа эмпирических данных}

Сбор эмпирических данных осуществлялся в период с 2014 по 2018 г. на базе средних школ г. Кирова и КОГОАУ ДПО «Институт развития образования (ИРО) Кировской области». Общий объем выборки - 415 учителей средних общеобразовательных школ. Из них 93.8\% женщин, средний возраст 43.4 года, 89.4\% имеют профильное высшее образование, что репрезентативно отображает ситуацию с педагогическими кадрами в школах области.

Анализ и интерпретация полученных данных проводились пошагово в логике комплексного системного исследования. Во-первых, устанавливались особенности структуры мотивации учителей в зависимости от трудового стажа и профессионализации. Во-вторых, определялись этапы динамики структуры МППД. В-третьих, выявлялись закономерности развития системы 
МППД в зависимости от трудового стажа. Так, структурный и функциональный анализ выступили необходимыми условиями реализации генетического плана изучения предметной области.

\section{Результаты}

\section{Динамика структурно-уровневой организачии МППД}

В эмпирическом исследовании анализировались уровни субсистем и компонентов, являющиеся, по мнению многих авторов (Карпов, 2015; Карпова, 2009; Разина, 2016; Петраш, 2017; и др.), ключевыми в системе, достаточными для исследования изменений, происходящих в структурно-уровневой организации мотивации учителей с течением времени.

Одним из основных с точки зрения выхода на генетический план изучения МППД стал метод структурного анализа (Карпов, 2004, 2015; Слепко и др., 2018). В результате его применения были установлены основные параметры компонентного и субсистемного уровней структуры мотивации деятельности учителей в зависимости от трудового стажа.

Анализ динамики общего количества составляющих структуры, количества взаимосвязей высокого уровня значимости между составляющими, колебания индексов когерентности и организованности, степени гомогенности/ гетерогенности, среднего веса компонентов и субсистем (таблица 1) позволяет утверждать о трансформации структуры МППД с увеличением трудового стажа и выделить ряд этапов развития системы МППд. Более подробно каждый этап охарактеризован А.В. Горбушиной (2018). Схематично этапы динамики структурной организации представлены на рисунке 2, где отражены не только базовые, но и доминирующие компоненты и субсистемы в составе МППД.

\section{Генез МППД}

На основе структурных показателей по составляющим компонентного и субсистемного уровней мотивации учителей с разным трудовым стажем путем сопоставления особенностей структуры и этапа динамики МППд с системогенетическими закономерностями осуществлялся генетический план изучения МППД педагогов во времени (в зависимости от трудового стажа). Рассмотрим его основные итоги.

Генез (от греч. происхождение, возникновение) мотивации профессиональной деятельности имеет общепсихологический характер, т.е. подчиняется тем же самым факторам развития, что и развитие личности в целом. В своей статье В.М. Розин (2016) на основе культурно-исторической концепции Л.С. Выготского рассматривает в качестве ключевых факторов развития личности культуру возраста, ситуацию социального воздействия и личность субъекта. В отношении субъекта труда данные факторы могут раскрываться в контексте ведущей деятельности взрослого человека - его профессиональной деятельности. Именно она закладывает собственную «культуру» взрослости и 
Таблица 1

Сводная таблица показателей структурного анализа мотивации профессиональной деятельности педагогов с разным трудовым стажем

\begin{tabular}{|c|c|c|c|c|c|c|c|c|c|}
\hline Стаж, годы & 1 & $1-2$ & $2-4$ & $4-5$ & $5-7$ & $7-10$ & $10-20$ & $\mathbf{2 0 - 3 0}$ & $>\mathbf{3 0}$ \\
\hline $\begin{array}{l}\text { Количество элементов } \\
\text { в структуре }\end{array}$ & 10 & 12 & 15 & 16 & 17 & 17 & 16 & 18 & 18 \\
\hline $\begin{array}{l}\text { Количество взаимосвя- } \\
\text { зей на высоком уровне } \\
\text { значимости }\end{array}$ & 32 & 18 & 31 & 31 & 39 & 24 & 59 & 77 & 67 \\
\hline ИКС & 57 & 32 & 57 & 51 & 77 & 43 & 131 & 176 & 178 \\
\hline ИдС & 0 & 0 & 4 & 8 & 6 & 2 & 2 & 0 & 0 \\
\hline ИОС & 57 & 32 & 53 & 43 & 71 & 41 & 129 & 176 & 178 \\
\hline \multirow{2}{*}{$\begin{array}{l}\text { Гомогенность/гетеро- } \\
\text { генность (значения } \\
\text { экспресс- } \chi^{2} \text { для пары } \\
\text { последующих групп) }\end{array}$} & \multicolumn{2}{|c|}{$\begin{array}{c}0.409 \\
\text { при } p \leqslant 0.05\end{array}$} & \multicolumn{2}{|c|}{$\begin{array}{c}0.608 \\
\text { при } p \leqslant 0.001\end{array}$} & \multicolumn{2}{|c|}{$\begin{array}{c}0.315 \\
\text { при } p \leqslant 0.05\end{array}$} & \multicolumn{2}{|c|}{$\begin{array}{c}0.932 \\
\text { при } p \leqslant 0.001\end{array}$} & - \\
\hline & - & \multicolumn{2}{|c|}{$\begin{array}{c}0.509 \\
\text { при } p \leqslant 0.01\end{array}$} & \multicolumn{2}{|c|}{$\begin{array}{c}0.879 \\
\text { при } p \leqslant 0.001\end{array}$} & \multicolumn{2}{|c|}{$\begin{array}{c}0.442 \\
\text { при } p \leqslant 0.05\end{array}$} & \multicolumn{2}{|c|}{$\begin{array}{c}0.861 \\
\text { при } p \leqslant 0.001\end{array}$} \\
\hline Базовые субсистемы & $\begin{array}{c}\text { BПM } \\
\text { BOM } \\
\text { BM }\end{array}$ & $\begin{array}{c}\text { MP } \\
\text { BOM } \\
\text { BПM } \\
\text { BM }\end{array}$ & $\begin{array}{c}\mathrm{BM} \\
\text { BOM } \\
\text { ВПМ }\end{array}$ & $\begin{array}{c}\text { BM } \\
\text { ВПМ }\end{array}$ & $\begin{array}{c}\text { BПМ } \\
\text { BOM } \\
\text { BM } \\
\text { MP }\end{array}$ & $\begin{array}{c}\mathrm{MP} \\
\mathrm{BOM} \\
\mathrm{BM}\end{array}$ & $\begin{array}{c}\text { BM } \\
\text { BOM } \\
\text { ВПM } \\
\text { MP }\end{array}$ & $\begin{array}{c}\mathrm{B \Pi M} \\
\mathrm{BM}\end{array}$ & $\begin{array}{l}\text { BM } \\
\text { BПM } \\
\text { BOM }\end{array}$ \\
\hline Ведущие субсистемы & - & - & - & - & - & - & - & - & - \\
\hline Средний вес субсистем & 12 & 7 & 11 & 8 & 13 & 7 & 25 & 29 & 26 \\
\hline Базовые компоненты & $\begin{array}{c}\text { ОПр } \\
\text { уд } \\
\text { ИК } \\
\text { ИН } \\
\text { ОП }\end{array}$ & $\begin{array}{c}\text { УАР } \\
\text { ИК } \\
\text { ПВЗ } \\
\text { УД }\end{array}$ & $\begin{array}{c}\text { ИК } \\
\text { ИН } \\
\text { УД } \\
\text { ОПр }\end{array}$ & $\begin{array}{l}\text { СкПр } \\
\text { ОП } \\
\text { Конк } \\
\text { Уд }\end{array}$ & $\begin{array}{c}\text { СкПр } \\
\text { ОП } \\
\text { ИК } \\
\text { Уд }\end{array}$ & $\begin{array}{c}\text { Ком } \\
\text { ПВЗ } \\
\text { Уд-ть } \\
\text { УД }\end{array}$ & $\begin{array}{l}\text { ДЗ } \\
\text { ОП } \\
\text { УД } \\
\text { ИК }\end{array}$ & $\begin{array}{c}\text { ДЗ } \\
\text { ОПр } \\
\text { Уд }\end{array}$ & $\begin{array}{c}\text { Д3 } \\
\text { СкПр } \\
\text { ОП }\end{array}$ \\
\hline Ведущие компоненты & - & - & МПБ & - & $\begin{array}{l}\text { Конк } \\
\text { УАР }\end{array}$ & ОПр & - & - & - \\
\hline $\begin{array}{l}\text { Средний вес } \\
\text { компонентов }\end{array}$ & 3 & 2 & 3 & 2 & 3 & 5 & 10 & 14 & 15 \\
\hline
\end{tabular}

Примечание. ИКС - индекс когерентности структуры, ИДС - индекс дифференцированности структуры, ИОС - индекс организованности системы, ВПМ - внешняя положительная мотивация, ВОМ - внешняя отрицательная мотивация, ВМ - внутренняя мотивация, МР мотивация работой, Ком - коммуникативный мотив, Конк - конкурентный мотив, МПБ мотивационный потенциал работы, УАР - уровень активации работой, ПВЗ - показатель взаимодействия с работой, Уд-ть - удовлетворенность работой, ДЗ - денежный заработок, СкПр стремление к продвижению, ИК - избегание критики, ИН - избегание наказания, ОПр - ориентация на престиж, УД - удовлетворение от работы, ОП - общественная полезность. 


\section{Этапы развития системы МППД}

Рисунок 2

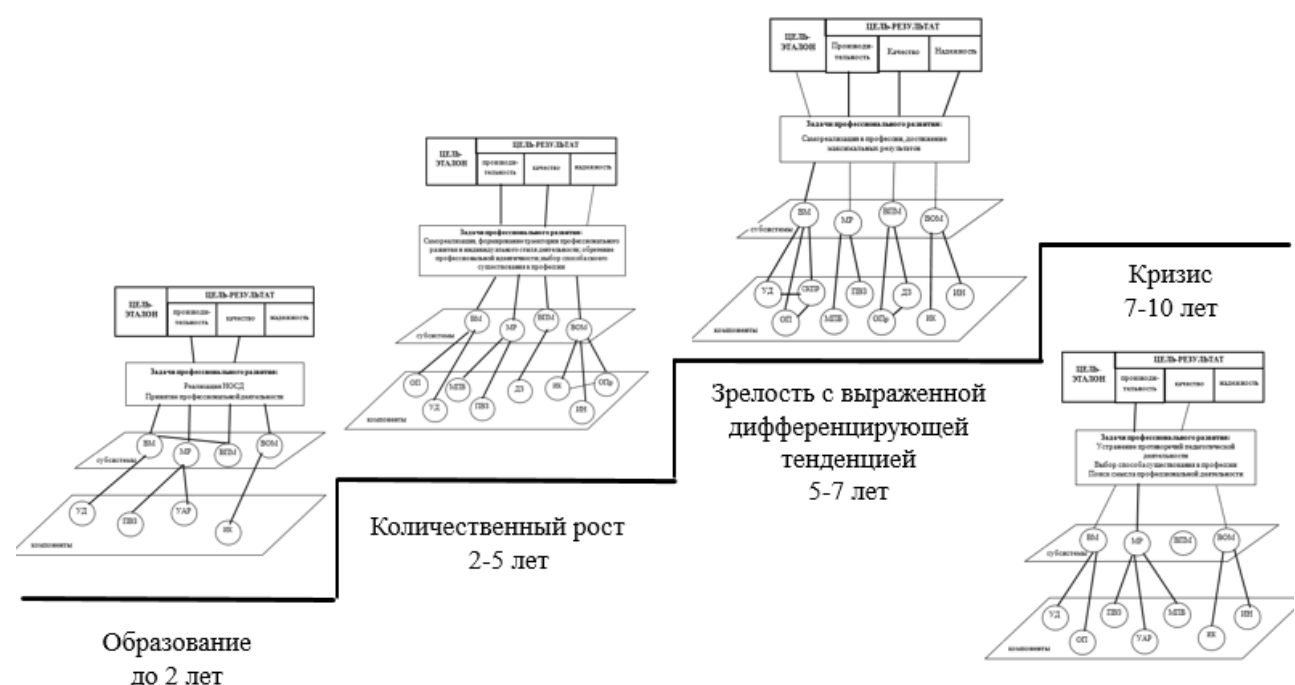

до 2 лет

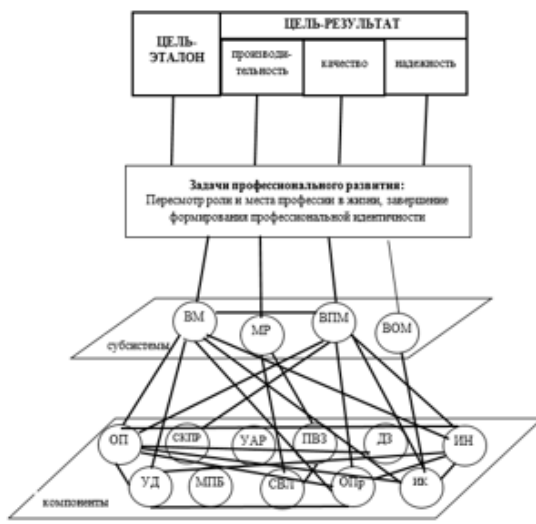

Реорганизация

от 10 до 20 лет

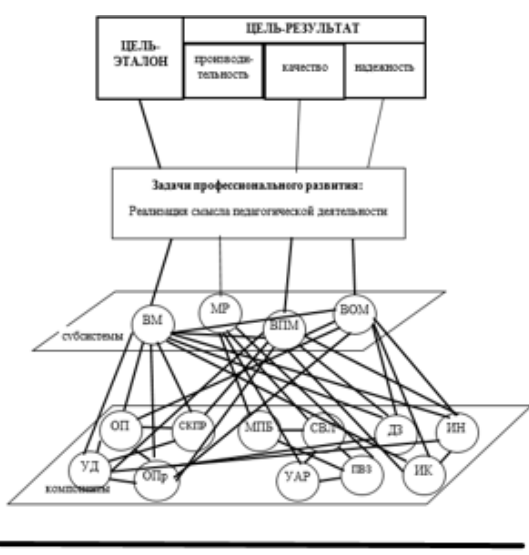

Зрелость с выраженной интеграционной составляющей свыше 20 лет

Примечание. ВПМ - внешняя положительная мотивация, ВОМ - внешняя отрицательная мотивация, ВМ внутренняя мотивация, МР - мотивация работой, Ком - коммуникативный мотив, Конк - конкурентный мотив, МПБ - мотивационный потенциал работы, УАР - уровень активации работой, ПВЗ - показатель взаимодействия с работой, СВЛ - степень владения работой, Уд-ть - удовлетворенность работой, ДЗ - денежный заработок, СкПр - стремление к продвижению, ИК - избегание критики, ИН - избегание наказания, ОПр - ориентация на престиж, УД - удовлетворение от работы, ОП - общественная полезность, СКПР - стремление к продвижению. 
создает особую социальную ситуацию развития: взаимодействие с коллегами и участниками образовательного процесса. В данном случае для описания генеза более конструктивна позиция А. В. Карпова (2015). При самостоятельном выполнении педагогической деятельности личность как открытая метасистема взаимодействует с более крупными метасистемами педагогической деятельности и метасистемой профессионального взаимодействия. В результате адаптации к изменившимся условиям ситуации внутри личности в мотивационной сфере формируется качественно новое образование - МППД, имеющее собственную специфику.

Генез МППД фиксируется по общему виду структуры мотивации профессиональной деятельности у педагогов со стажем от 1 до 2 лет (таблица 1, рисунок 2). На уровне субсистем выделяется субсистема мотивации работой, которая является базовой в структуре, тогда как у учителей со стажем до 1 года данная специфическая субсистема отсутствует (Горбушина, 2018). На основании имеющегося у И. П. Пономарева (2004) понимания сущности мотивации работой можно утверждать именно о возникновении мотивационного новообразования МППД у педагогов со стажем от 1 до 2 лет, поскольку появление в структуре субсистемы мотивации работой фиксирует упрочение интереса субъекта к содержанию и процессу выполнения именно педагогической деятельности.

Дальнейшие изменения в МППД при общем рассмотрении заключаются в установлении компонентного состава структуры, формировании взаимосвязей между составляющими, интеграции составляющих в функциональные объединения в плане достижения цели, т.е. они протекают как системогенез в его классическом понимании. Следовательно, при описании изменений в МППД правомерно транспонировать на данную предметную область принципы системогенеза. В то же время для МППД как системы со встроенным метасистемным уровнем могут быть применимы и закономерности метасистемогенеза. Рассмотрим принципы происходящих изменений в структуре МППД более подробно.

\section{Закономерности развития МППД}

А.В. Карпов (2015) выделяет и описывает два уровня закономерностей динамики для систем со встроенным метасистемным уровнем. Так, на уровнях компонентов и субсистем МППД (рисунок 1) будут действовать принципы системогенеза, а на собственно системном и метасистемном уровнях - принципы метасистемогенеза.

В первую очередь нас интересует генетическая динамика структуры мотивации профессиональной педагогической деятельности на субсистемном и компонентном уровнях, где развитие описывается закономерностями системогенеза: неравномерности, гетерохронности, одновременности закладки компонентов, иерархизации, уровневой дифференциации, конкордантности, консолидации, прогрессирующей интегрированности и дифференцированности, обеспечения минимальной достаточности в функционировании системы, переструктурирования (Разина, 2016). Данные принципы имеют устоявшийся характер и верифицированы в многочисленных исследованиях (Карпов, 2004, 2015; Карпова, 2009; Разина, 2016; Петраш, 2017; и др.). 
Большинство закономерностей системогенеза, выделенных ранее, нашли подтверждение и в данном исследовании.

Одним из наиболее простых, наглядно проиллюстрированных (рисунок 1) принципов динамики МППД можно считать принцип постоянного переструктурирования (Разина, 2016): структура мотивации профессиональной деятельности для каждой стажевой группы учителей имеет разный набор составляющих, взаимосвязей между ними, за счет чего проявляется ее качественное своеобразие, возникающее как ответ на требования деятельности к субъекту труда и задачи его личностного и профессионального развития. Переструктурирование содержания компонентного и субсистемного уровней МППД прослеживается настолько явно, что кажется естественным и не нуждается в дополнительных подтверждениях примерами.

При представлении структурно-уровневой организации мотивации деятельности у учителей уже на первом году труда была зафиксирована структура. Ее можно охарактеризовать как протоструктуру, поскольку в ней содержатся исключительно общетрудовые мотивы и субсистемы, имеющие многочисленные статистически значимые взаимосвязи между собой (Горбушина, 2018). У учителей со стажем труда от 1 до 2 лет структура отличается: в ней присутствует специфическая субсистема мотивации работой, связанная с содержанием педагогической деятельности, а взаимосвязи между составляющими более дифференцированы. При проведении диагностического среза структура фиксируется одномоментно, что сопровождается повышением индекса гомогенности при уменьшении индекса когерентности (таблица 1). Кроме того, составляющие, возникшие в структуре мотивации деятельности у учителей со стажем от 1 до 2 лет, появляются и на дальнейших этапах ее изменения, что дает основание говорить об одновременности закладки основных составляющих структуры МППД.

Изменения в содержании структуры мотивации деятельности учителей носят неравномерный характер: периоды роста и интенсивного наращивания количества доминирующих и базовых составляющих структуры МППД сменяются периодами «инволюции»: структура становится менее содержательной, распадаются устоявшиеся связи. Неравномерность динамики можно зафиксировать по постоянной смене от этапа к этапу количества составляющих и взаимосвязей между ними, по колебаниям индексов когерентности, дифференцированности и организованности системы, по изменению среднего веса субсистем в ее составе (таблица 1). Данная тенденция проявляется в течение всего развития МППД, но наиболее ярко неравномерность развития проступает при смене этапа зрелости кризисом (Горбушина, 2018) и следующим за ним переструктурированием системы. Периоды эволюции и инволюции, экстенсивных и интенсивных трансформаций структуры имеют разные временны́е границы и длительность по сравнению друг с другом. Наиболее быстро наращивание и изменения в системе МППД происходят в первые 5-7 лет самостоятельной педагогической деятельности (рисунок 2). Обозначенные особенности позволяют сделать вывод о развитии МППД по принципу неравномерности.

Актуализация различных мотивационных образований, выделение субсистем, их дифференциация в составе МППД были выявлены на разных этапах 
динамики системы мотивации профессиональной педагогической деятельности. Отдельные мотивы и субсистемы в составе мотивации учителей вызревают и выполняют функциональные роли доминирующих, базовых и ведущих в различные временны́е промежутки. Например, мотивация работой как одна из базовых субсистем доминирует в структуре МППД на этапе образования и на этапе мотивационного кризиса (таблица 1, рисунок 2). Мотив активации работой, входящий в данную субсистему, относится к базовым только на этапе образования, что позволяет специфически охарактеризовать проявления субсистемы мотивации работой: для учителей со стажем до 2 лет более значимо освоить нормативно одобренный способ выполнения педагогической деятельности, достичь определенного уровня результативности, добиться устойчивых показателей производительности и качества выполнения профессиональной деятельности. Для педагогов со стажем от 7 до 10 лет (в период мотивационного кризиса) мотивация работой имеет иное функциональное проявление, обусловленное связью базовых мотивов мотивационного потенциала, активации и взаимодействия с работой. С одной стороны, учитель погружен в педагогическую деятельность, с другой стороны, актуализация одновременно с субсистемой отрицательной субсистемы МППД может провоцировать разрушение интереса к профессиональной деятельности. Более детальный анализ содержания структуры компонентного и субсистемного уровней структуры мотивации учителей, представленных в таблице 1 в количественном выражении и на рисунке 2 в графическом виде, показывает различное время для вызревания отдельных мотивов и субсистем при постоянном присутствии в структуре других (например, мотив удовлетворения от работы имеет статус доминирующего на всем временно́м континууме). Выявление двух качественно специфических состояний зрелости системы (зрелость с выраженной тенденцией к дифференциации и зрелость с выраженной тенденцией к интеграции составляющих) с различным временны́м интервалом также позволяет сделать заключение о гетерохронности динамики структуры МППД.

На протяжении всего временно́го континуума фиксируются периоды инволюции отдельных мотивов, т.е. выхода мотивационных образований за рамки доминирующих либо базовых, исключения их из структуры мотивации учителей. Так, например, мотив ориентации на престиж присутствует в структуре у педагогов со стажем до 1 года, затем исчезает из числа актуализированных и вновь появляется в структуре только на этапе количественного роста у учителей со стажем от 2 до 4 лет, затем вновь исчезает и появляется уже у педагогов со стажем от 20 до 30 лет (таблица 1). Подобная инволюция мотива ориентации на престиж объясняется сменой задач профессионального развития, стоящих перед учителем в обозначенных временных периодах. Так, для педагогов со стажем до 1 года наиболее важно закрепиться в должности, освоить нормативно одобренный способ деятельности и подтвердить собственный статус, поэтому престиж учительской профессии важен и побуждает к деятельности. Для учителей со стажем от 2 до 4 лет особое значение имеют самореализация в профессии, построение траектории профессионального развития, выбор собственного способа существования в профессии. Для педагогов со стажем от 20 
до 30 лет, когда стоит задача сохранения собственного статуса и реализации смысла педагогической деятельности, ориентация на престиж может актуализироваться за счет получения статуса наставника. Наряду с инволюцией незадействованных мотивационных образований для структуры МППД характерным в отдельные временны́е промежутки является «облегчение» структуры: уменьшение количества составляющих и взаимосвязей между ними (таблица 1) у учителей со стажем от 1 до 2 лет, от 7 до 10 лет. Однако при этом структура существует и функционирует. Инволюция «незадействованных» мотивационных образований, «облегчение» каркаса структуры, дальнейшая минимизация состава и содержания структуры МППД на этапе мотивационного кризиса (таблица 1, рисунок 2) у педагогов со стажем от 7 до 10 лет свидетельствуют об обеспечении минимального эффекта функционирования системы мотивации.

Постепенное нарастание дифференциации функциональных субсистем внутренней мотивации, мотивации работой, внешней положительной и отрицательной мотивации до достижения кризиса, зафиксированное через динамику индекса дивергентности (таблица 1), также является подтверждением принципов системогенетического развития МППД. Кроме того, отдельные мотивы входят в состав определенных субсистем. Например, мотив удовлетворения от труда входит в состав внутренней мотивации на всех этапах развития структуры МППД. Внутренняя мотивация как субсистема наиболее дифференцирована на этапе зрелости у педагогов со стажем от 5 до 7 лет. В ее состав входят: мотив удовлетворения от труда, осознание общественной полезности собственной работы и стремление к продвижению. Подобную тенденцию можно проследить в отношении всех остальных основных субсистем в составе МППД на данном временно́м этапе. Другими словами, можно утверждать, что изменения в структуре МППД до периода мотивационного кризиса происходят по принципу увеличения дифференциации в формировании субсистем, проявлении их качественного своеобразия, что необходимо для вызревания функциональной специфики системы МППД.

До достижения кризиса наряду с повышением качественного своеобразия субсистем ярко наблюдается выстраивание вертикальных отношений между составляющими компонентного и субсистемного уровней: образования, выступающие в роли мотивов, объединяясь, образуют функционально специфические субсистемы, качественно отличающиеся по содержанию на разных этапах. Например, для педагогов с небольшим стажем труда (до 2 лет) сущность внешней отрицательной мотивации связана с избеганием критики, тогда как для учителей со стажем от 2 до 5 лет ее характеристика меняется (рисунок 2): значимо не только отсутствие критики, но и избегание наказания и ориентация на престиж. Объединяясь, они позволяют описать мотивационную тенденцию «держаться за рабочее место», если оно кажется для учителя значимым, престижным. Для педагогов с большим стажем труда на этапе зрелости с выраженной тенденцией к интеграции структуры в составе внешней отрицательной мотивации присутствуют уже не только обозначенные ранее компоненты, но и заработок, и осознание полезности своей работы, что придает субсистеме новое своеобразие: для учителя важно не только не подвергаться 
критике и избегать наказания, дорожить рабочим местом, но и получать оплату за свою работу, понимать полезность и важность собственной работы для других. Так, вертикальные отношения между комнонентами и субсистемами позволяют последним на различных этапах динамики по-разному характеризовать проявления системы МППД. Выстраивание вертикальных отношений между составляющими является признаком установления иерархии в системе МППД. Кроме того, на каждом этапе динамики можно установить иерархию внутри уровней по функциональному признаку: выделить ведущие и базовые составляющие. Ведущие составляющие системы могут оказывать прямое влияние на функционирование системы МППД в зависимости от стажа, тогда как базовые составляющие имеют больший удельный вес в структуре (Слепко и др., 2018), это является еще одним подтверждением функционирования системы по принципу иерархизации. Иерархизация структуры сохраняется на всех этапах изменения мотивации деятельности учителей, однако характер ее меняется: качественный скачок в развитии системы запускает выраженную интеграцию внутри субсистем.

Увеличение значений индекса когерентности (таблица 1) на первых этапах планомерное, а после кризиса резкое - указывает на прогрессирующую интеграцию системы мотивации деятельности педагогов с разным трудовым стажем. Интеграция проявляется в резком увеличении количества взаимосвязей как внутри уровня между составляющими, так и между уровнями, между субсистемами, а также в увеличении количества взаимосвязей межу субсистемами и составляющими других субсистем (рисунок 2). Данный факт позволяет утверждать, что с увеличением стажа трудовой деятельности после мотивационного кризиса (после 10 лет стажа) побуждать к выполнению профессиональной деятельности могут самые разные мотивы, но в каком качестве и в составе какой субсистемы, определяющей качественное своеобразие проявления мотивации, трудно спрогнозировать. Однако возрастающая степень общности может позволить актуализировать «необходимые», конструктивные с точки зрения реализации педагогической деятельности мотивы и субсистемы в процессе проектирования системы управления мотивацией. Возрастающая степень общности свидетельствует о функционировании системы МППД по принципу прогрессирующей интеграции.

Динамика структуры МППД в соответствии с целью психологической системы профессиональной деятельности, изменением условий ситуации и задачами профессионального развития может считаться проявлением конкордантности функционирования системы и подчинения ее целевой детерминации. На рисунке 1 отражены вертикальные взаимоотношения, показано достижение согласованности функционирования составляющих МППД в плане решения задач собственного профессионального развития и реализации отдельных параметров целей педагогической деятельности. Приведем пример согласованности изменений, происходящих в субсистемном и компонентном уровнях структуры мотивации учителей, в соответствии с целями и задачами педагогической деятельности. Так, для учителей со стажем до 1 года, только приступивших к выполнению должностных обязанностей, необходимо достичь общей цели - начать обучать и получать результаты обучения в 
классе. В свете данной цели перед педагогом стоят задачи профессиональной деятельности: освоение нормативно одобренного в данной школе способа выполнения педагогической деятельности на требуемом уровне и получение определенных результатов производительности - проведение уроков, контроль знаний и др. В соответствии с данными задачами при выполнении должностных обязанностей и ориентации на производительность у учителя актуализируются уже имеющиеся общетрудовые мотивы и мотивационные субсистемы. Далее, с погружением в профессиональную деятельность и увеличением стажа труда до 1-2 лет, цели и задачи педагогической деятельности меняются: необходимо не просто освоить работу учителем, но уже получать стабильные результаты труда при повышении его качества, принять собственную работу, постичь ее суть и сформировать личностный смысл профессиональной деятельности. Соответственно обозначенным целям и задачам меняется и содержание структуры мотивационной сферы. Возникают новые мотивы, связанные непосредственно с содержанием педагогической деятельности, они объединяются в новую субсистему, перестраиваются также взаимосвязи в имеющихся субсистемах, так формируется МППД. Подобная тенденция детерминации изменений характерна на всем протяжении динамики структуры МППД: трансформации происходят не спонтанно, но закономерно, в соответствии с изменениями целей и задач педагогической деятельности, т.е. по принципу конкордантности и целевой детерминации.

При анализе структуры мотивации деятельности учителей, проведенном А.В. Горбушиной (2018), прослеживается закономерность реверсивности в динамике содержания структуры МППД. Итоги предыдущего этапа развития становятся элементом содержания структуры и в случае невостребованности отходят на задний план. В таблице 1 отражено это движение: компоненты, игравшие роль базовых на предыдущих этапах динамики, на последующих могут стать ведущими в системе МППД, а затем переходить в разряд базовых. Так, у учителей со стажем от 4 до 5 лет на этапе количественного роста структуры МППД среди базовых мотивов появляется мотив конкуренции, который на следующем этапе динамики системы оказывается среди ведущих, т.е. может оказывать влияние на профессиональную деятельность учителя: повышение собственной конкурентоспособности, свои достижения становятся значимыми для педагога. Однако на этапе мотивационного кризиса мотив конкуренции исчезает из структуры, поскольку для учителя, осмысляющего результаты и противоречия выполнения педагогической деятельности, конкурирование перестает быть актуальным. Необходимо отметить также, что после прохождения этапа мотивационного кризиса развитие системы МППД идет в той же последовательности, что и до кризиса, через стадии реорганизации, роста и достижения зрелости, хотя и на качественно ином уровне. Именно в повторении, возврате к прошлому на качественном новом уровне можно проследить действие принципа реверсивности в динамике структуры МППД.

Подтвержденным можно считать и принцип кумулятивности в системогенезе МППД. На каждом последующем этапе в содержании структуры мотивации учителей накапливаются результаты развития, которые являются основой 
для качественного изменения ее содержания в дальнейшем. Так, на подготовительном этапе происходит гомеокинез в виде постепенного накопления трансформаций общетрудовых мотивов, актуализированных в педагогической деятельности. По достижении критической массы эти изменения приводят к возникновению новообразования - собственно МППД (рисунок 2). Стремление системы к аккумулированию ресурсов мотивационных образований проявляется также в общей последовательности стадий трансформации системы: этапы зрелости как апогей накопления составляющих в структуре компонентного и субсистемного уровней не только представляют собой результат предыдущего развития, но и являются пространством для дальнейших трансформаций. Например, по достижении зрелости структурой мотивации у учителей со стажем от 5 до 7 лет система переходит в состояние гетеростаза, в результате чего на каркасе прошлой формируется новая структура МППД. Другими словами, закономерность кумулятивности является одной из значимых в описании динамики структуры МППД.

Кроме того, в ходе анализа результатов диагностики мотивации учителей нашел свое подтверждение принцип итеративности, предполагающий многократное повторение уже пройденного. Итеративность как «множественная повторяемость закономерностей развития в масштабе времени» (Шадриков, 2017; Карпов, 2015) в нашем случае может заключаться в постоянстве актуализации определенных мотивационных образований. Так, среди базовых субсистем в структуре МППД постоянно присутствует внутренняя мотивация, имеющая источником личностные ресурсы. Внешняя положительная мотивация также относится к числу базовых практически на каждом этапе динамики, за исключением этапа мотивационного кризиса, что может указывать, с одной стороны, на личностную детерминацию кризиса, с другой стороны, на необходимость подключения организационных стимулов поддержания мотивации на данном этапе. Среди мотивов профессиональной педагогической деятельности наиболее востребованным на протяжении всего периода динамики структуры МППД может считаться мотив удовлетворения от работы, который относится к числу базовых компонентов на каждом этапе системогенеза МППД. Многократную повторяемость можно также проследить в выстраивании общего характера развития в виде стадий: образование - рост - зрелость - кризис, являющихся универсальным вектором системогенеза (Разина, 2016).

На наш взгляд, в данном исследовании динамики компонентного и субсистемного уровней структуры мотивации деятельности учителей просматривается уже не столько итеративность, сколько цикличность развития МППД. В таблице 1 и на рисунке 2 зафиксированы два крупных по своему содержанию цикла в развитии МППд. Первый цикл занимает период до 7 лет трудового стажа, и здесь происходят в большей степени количественные изменения в структуре: постепенно нарастают когерентность, организованность, специфичность состава компонентного и субсистемного уровней МППД. Система имеет ярко выраженную тенденцию к дифференциации, а ее функционирование зависит в наибольшей степени от внешних факторов. После кризиса наступает второй цикл, когда трансформация системы происходит в качественном 
плане с выраженной тенденцией к интеграции и «прорастанию» в мотивационную сферу личности. После достижения системой зрелости внешние факторы отходят на второй план, не угрожая устойчивости системы, и развитие определяется в большей степени внутренними факторами, связанными с особенностями личности, смыслообразованием, формированием профессиональной идентичности и собственной траектории профессионального развития. У учителей со стажем свыше 10 лет структура МППД достаточно интегрирована; при актуализации отдельного мотива побуждаются взаимосвязанные с ним мотивационные образования и субсистемы, т.е. система может регулировать саму себя, выходя на качественно новый виток функционирования. В связи с этим возможности внешнего управления мотивацией могут быть ограничены. Регуляция МППД возможна исключительно опосредованно, через работу с личностью учителя.

Прохождение качественно различных циклов трансформации МППД можно считать принципом развития более высокого порядка, не только учитывающим внутренние процессы, происходящие в системе под воздействием внешних факторов, но и описывающим сложное взаимодействие внешних факторов влияния и сложившихся внутренних особенностей системы. А.В. Карпов относит данный принцип к принципам метасистемогенеза, доказывающим сложный и поливариативный характер развития сложноорганизованных систем (Карпов, 2015), имеющих свойства саморегуляции и самоуправления.

По сути, принципы метасистемогенеза являются продолжением и трансформацией системогенетических закономерностей для описания более высокоорганизованного метасистемного уровня общей модели МППД. Генезис систем со «встроенным» метасистемным уровнем характеризуется тем, что в нем в значительной степени сохраняются принципы, описанные в концепции системогенеза. Однако сами эти принципы раскрываются новыми, дополнительными гранями; выходят за рамки своего исходно установленного содержания, а иногда приобретают свою инверсионную форму (Карпов, 2015). Охарактеризуем данные принципы более подробно: насколько они применимы к описанию динамики системы мотивации деятельности учителей в соответствии с трудовым стажем.

Мультипликативность в развитии МППд заключается в представленности «целого» (системы МППД) в каждой из составляющих. «Благодаря своеобразному распределению общего функционального ресурса вдоль “оси времени”, система получает возможность как бы многократной, множественной реализации их потенциала, ресурса» (Карпов, 2015, с. 93). Получается, что в каждом из компонентов отражается общий характер структуры МППД. В данном случае можно констатировать, что общий характер структуры МППД будет определяться представленностью и соотношением функциональных субсистем в собственном составе и отражаться в характеристике базовых мотивов. Например, на этапе кризиса у педагогов со стажем от 7 до 10 лет общая система МППД может характеризоваться «незадействованностью», «инволюцией» внешней положительной мотивации, по сути являться неуправляемой извне: стимулирующие организационные воздействия не будут иметь силы, поскольку не представлены в структуре. В то же самое 
время общий характер структуры отражается в ее компонентах: на этом уровне у учителей актуализированы мотивы, связанные, в первую очередь, с характером самой педагогической деятельности и личностью учителя. Для респондентов, участвовавших в исследовании, оказалось наиболее важным получать удовлетворение от собственной деятельности, оказывать влияние на содержание и характер работы, взаимодействовать с коллегами в процессе выполнения работы. Со стороны может показаться, что на данном этапе система «закрыта» для внешнего воздействия, поскольку сосредоточена на ликвидации возникшего дисбаланса структуры. Далее, на этапе реорганизации, у учителей со стажем от 10 до 20 лет происходит переструктурирование системы, резкое повышение интегрированности и организованности, увеличение степени ее гомогенности (по сравнению с предыдущим этапом), зафиксированное в количественных индексах в таблице 1, что отражается и в характере содержания компонентов: многие мотивы взаимосвязаны не только с базовыми субсистемами, но и между собой, образуя специфические комплексы. Например, для педагогов со стажем от 10 до 20 лет важно не просто получать удовлетворение от результата собственной деятельности, но и понимать пользу от своей работы, осознавая престиж труда учителя; не просто получать удовлетворение от результата своей деятельности, но и иметь возможность занимать определенный статус в коллективе и работать относительно свободно, не думая о санкциях и наказаниях. Подобные комплексы мотивов необходимо учитывать при организации управления мотивацией учителей. Другими словами, усложненный интегрированный характер структуры МППД отражается и в интеграции мотивов на компонентном уровне в более сложные комплексы, что свидетельствует о развитии системы МППД по принципу мультипликативности.

Значимым в понимании развития системы МППД является принцип ситуационной детерминации (трансформирующейся детерминации). Как отмечалось выше, при обретении зрелости системой МППД побуждение или детерминация деятельности зависит сразу от нескольких факторов: особенностей выполнения деятельности, социального взаимодействия и задач профессионального развития. Накладываясь друг на друга, они образуют особую ситуацию, на которую система МППД в силу своей сформированности и устойчивости реагирует. После переживания системой МППД кризиса к факторам детерминации добавляется сама система МППД, которая может регулировать сама себя, выполняя метасистемную функцию. В силу зрелости, интегрированности составляющих недостаток мотивационных образований восполняется взаимосвязанными с ними составляющими. Таким образом, ситуационная детерминация становится трансформирующейся: крайне сложно ответить на вопрос, какими именно мотивами и мотивационными субсистемами побуждается деятельность учителя и как на нее воздействовать в этот период.

Гетерархия сменяет принцип иерархии в сверхсложных системах, показывая выстраивание вертикальных взаимоотношений в структуре в зависимости от более крупных факторов-предикторов или условий ситуации. В данном исследовании гетерархию можно проследить частично на основании представленной модели структуры МППД и ее экспликации в деятельности (рисунок 1). 
Иерархия между уровнями в плане определения базовых и ведущих компонентов и субсистем устанавливается в зависимости от особенностей выполнения педагогической деятельности, социального взаимодействия и задач профессионального развития учителя. Существование принципа гетерархии позволяет обосновать действенность факторов общепсихического развития личности и на систему МППД в том числе. Так, на этапе реорганизации структуры МППД у педагогов со стажем от 10 до 20 лет изменение целей деятельности (выполнение педагогической деятельности на высоком уровне производительности, качества и надежности), задач профессионального развития (пересмотр смысла педагогической деятельности, завершение формирования профессиональной идентичности и достижение мастерства), изменение профессиональной ситуации (получение профессионального статуса, признание среди коллеги и участников образовательного процесса, достижение определенных результатов труда), а также сформированная ранее структура выступают предикторами дальнейшего переструктурирования компонентного и субсистемного уровней МППД. Многоплановость действия предикторов отражается и на широкой представленности базовых мотивов и субсистем, увеличении взаимосвязей внутри уровней и между уровнями структуры, в результате чего структура приобретает черты устойчивости и определенной избыточности содержания. Выстраивание иерархии в соответствии с изменением целого спектра предикторов указывает на трансформацию принципа иерархии в закономерность гетерархии.

Принцип пропорциональной интегрированности, являющийся, на первый взгляд, антагонистом принципа дифференциации, позволяет утверждать существование разнонаправленных тенденций в развитии МППД в зависимости от трудового стажа. Если на первых этапах дифференциация более значима, поскольку система должна приобрести свою качественную определенность, то на более поздних этапах динамики (после прохождения кризиса) система функционирует как высокоинтегрированная целостность, имея возможность быть относительно устойчивой под воздействием внешних факторов и сохранять свою автономность. Так, четкая дифференциация структуры на этапе зрелости у учителей со стажем от 5 до 7 лет может быть противопоставлена этапу зрелости структуры МППД у педагогов со стажем свыше 20 лет, у которых интеграция структуры достигает своего апогея. В данный временной отрезок педагогическая деятельность часто поддерживается ресурсами максимально интегрированной мотивационной системы в условиях дефицита стимулирующих организационных факторов. Правомерно утверждать, что развитие системы МППД осуществляется по принципу пропорциональной интеграции.

Тесно связан с принципом интегрированности и принцип заведомой избыточности, суть которого заключается в возможности подключать разнообразные мотивационные диспозиции для побуждения деятельности. В развитии МППД на втором цикле динамики заведомая избыточность явно прослеживается в богатом содержании и тесной взаимосвязи компонентов и субсистем МППД (рисунок 2), благодаря чему педагогическая деятельность учителей со стажем свыше 10 лет будет активизироваться самыми разнообразными мотивами и функциональными субсистемами. Заведомая избыточность содержания 
компонентного и субсистемного уровней структуры, как было отмечено выше, позволяет системе МППД быть устойчивой и функционировать в условиях дефицита организационных стимулов актуализации мотивации учителей-стажистов.

На уровне анализа системы МППД в целом динамика ее структуры представляется достаточно равномерной с точки зрения временны́х колебаний. Если первый цикл развития, оканчивающийся кризисом, как было обозначено выше, укладывается в десять лет, то второй цикл развития с меньшей интенсивностью, но более выраженными изменениями в структуре длится также около десяти лет, по истечении которых структура системы вновь приобретает зрелость. Равномерность также прослеживается в поступательном увеличении степени интеграции, организованности, гомогенности состава уровней от этапа к этапу внутри циклов развития системы МППД (таблица 1). Можно заключить, что развитие системы МППД в целом происходит по принципу равномерности во времени.

На основе анализа результатов эмпирического исследования можно также утверждать, что динамика системы МППД происходит по принципу синхронности. Выше было показано, что трансформации в структуре мотивации учителей согласуются с изменением предикторов ее возникновения. Смена особенностей выполнения деятельности, социального взаимодействия и задач профессионального развития влечет за собой трансформацию структуры системы в целом. Практическое совпадение во времени изменения факторовпредикторов и переструктурирования содержания компонентного и субсистемного уровней структуры мотивации учителей дает основание утверждать о некоторой синхронности изменения внешних факторов и трансформации МППД. Другими словами, меняя внешние условия, можно воздействовать на структуру МППД, что дает возможности для управления ею.

Таким образом, происходящие с возрастанием трудового стажа изменения в содержании структуры мотивации деятельности учителей по своему характеру можно назвать не только системогенезом, но и метасистемогенезом, подтверждающим сложную организацию и нелинейное развитие мотивации профессиональной педагогической деятельности.

\section{Обсуждение}

Исследования профессиональной мотивации педагогов общеобразовательных школ в последние десять лет позволяют лишь частично сопоставить полученные данные об изменениях МППД с уже имеющимися знаниями в области профессиональной мотивации учителей.

Так, в работе С.В. Львовой (2015) установлено, что показатели основных субсистем мотивации изменяются со временем в определенном соотнесении. С увеличением трудового стажа незначительно, но все же снижается показатель внутренней мотивации, внешней положительной мотивации и внешней отрицательной мотивации, но не указано, что может быть причиной этих изменений и насколько они закономерны. Исследование С.В. Львовой позволяет констатировать факт динамики мотивационных образований. В представленном 
нами исследовании изменения показателей мотивации профессиональной деятельности также явно прослеживаются, но приобретают вид закономерных.

В публикации А.В. Левченко (2015) показано, что колебания показателей основных субсистем мотивации нелинейны. У педагогов со стажем от 6 до 15 лет происходит снижение показателей внутренней и внешней положительной мотивации, а у педагогов со стажем более 16 лет - повышение. Автор не указывает причин изменения показателей. При проведении более глубокого анализа и сопоставлении результатов данного исследования с исследованием А.В. Левченко выявляется, что таким образом количественно был зафиксирован происходящий в данном временном промежутке мотивационный кризис. Установленные автором особенности профессиональной мотивации педагогов вполне объяснимы с позиций системогенеза МППд.

В исследовании профессиональной мотивации А.П. Кожевиной и С.В. Дубровиной (2018) описаны актуализированные мотивы и мотивационные ориентации современных учителей общеобразовательных учреждений. Однако полученные данные по выраженности отдельных мотивов вступают в противоречие с описанными выше. Например, среди актуализированных мотивов представленной выборки наименее выражен мотив удовлетворения от труда, тогда как в нашем исследовании он является одним из базовых и стабильно присутствует в структуре мотивации деятельности учителей.

Полученные в данном исследовании результаты в целом не противоречат более ранним исследованиям, но позволяют утверждать, что вскрытие темпоральных закономерностей динамики структуры мотивации деятельности учителей предоставляет большие объяснительные возможности в многомерном исследовании МППД.

\section{Заключение}

Концептуальная «развертка» предметной области позволила сформулировать ряд выводов в отношении описания генезиса и темпоральных закономерностей изменения мотивации профессиональной деятельности педагогов. Вопервых, установлено, что система МППД формируется и модифицируется в соответствии с общепсихическими и профессиональными факторами развития: изменениями социального взаимодействия, задач профессионального развития, изменяющихся по мере увеличения стажа педагогической деятельности. Во-вторых, определено, что генетические изменения в системе МППД происходят нелинейно, гетерохронно, конкордантно, по принципам одновременности закладки компонентов, нарастающей дифференциации и интеграции и др. В-третьих, показано, что содержание структуры МППд на ранних этапах целиком подчиняется базовым принципам системогенеза, на поздних этапах принципам метасистемогенеза, описывающим развитие сложноорганизованных систем.

Генетический анализ МППД позволяет существенно расширить представление о мотивации педагогов: выявить предикторы генезиса и показать характер ее изменений во времени. 
Знания о генезе и темпоральных закономерностях развития МППД могут быть использованы в различных аспектах. На уровне менеджмента при формировании стратегии воздействия на мотивацию извне: посредством создания особых условий выполнения деятельности, социальной ситуации, обозначения задач профессионального развития для учителей. На уровне администрации школ понимание закономерностей динамики структуры МППД позволит создавать меры организационной поддержки мотивации педагогов с разным стажем. На уровне индивидуальной работы с психологом представление о нелинейности развития мотивации учителя открывает возможности для актуализации отдельных составляющих МППД и психологического сопровождения деятельности учителя, что может стать предметом специального обсуждения.

\section{Литература}

Горбушина, А. В. (2011). Структура мотивации профессиональной деятельности: метасистемный подход. Вестник Вятского государственного гуманитарного университета, 3(3), 138-141.

Горбушина, А. В. (2018). Развитие системы мотивации профессиональной деятельности в контексте педагогической деятельности. Сибирский педагогический журнал, 5, 83-95. doi:10.15293/1813-4718.1805.09

Карпов, А. В. (2004). Метасистемная организащия уровневых структур психики. М.: ИП РАН.

Карпов, А. В. (2015). Психология деятельности: монография (т. 3). М.: РАО.

Карпова, Е. В. (2009). Структура и генезис мотивационной сферы личности в учебной деятельности (Докторская диссертация). Ярославский государственный педагогический университет им. К.Д. Ушинского, Ярославль.

Кожевина, А. П., Дубровина, С. В. (2018). Мотивация профессиональной деятельности педагогов общеобразовательных организаций. Общество: социология, психология, педагогика, 5, 39-45.

Кокурина, И. Г. (1984). Социально-психологические аспекты мотивации трудовой деятельности (Кандидатская диссертация). Московский государственный университет им. М.В. Ломоносова, Москва.

Левченко, А. В. (2015). Особенности профессиональной мотивации педагогов. Краеведение Приамурья, 1(29), 23-27.

Ломов, Б. Ф. (1984). Методологические и теоретические проблемы психологии. М.: Наука.

Львова, С. В. (2015). Профессиональная мотивация педагогов образовательного учреждения. Системная психология и социология, 3, 54-62.

Марук, А. С., Правдина, Л. Р. (2015). Особенности мотивации профессиональной деятельности молодых педагогов. Научный альманах, 10-4(12), 392-395.

Метеличев, В. В., Шингаев, С. М. (2014). Мотиващия профессиональной деятельности и профессиональное выгорание педагогов: теория, диагностика, взаимосвязь, профилактика. СПб.: СПб АППО.

Петраш, Е. А. (2017). Социальная идентичность в норме и при нарушении (Докторская диссертация). Ярославский государственный университет им. П. Г. Демидова, Ярославль.

Пономарев, И. П. (2004). Мотивация работой в организации. М.: Едиториал УРСС.

Разина, Т. В. (2016). Структурно-функциональная организация и генезис мотивации научной деятельности (Докторская диссертация). Ярославский государственный университет им. П.Г. Демидова, Ярославль. 
Реан, А. А. (1999). Психология изучения личности. СПб.: Изд-во Михайлова В. А.

Розин, В. М. (2016). От взглядов Выготского к современной концепции развития. Психология. Журнал Высшей школы экономики, 13(2), 367-385.

Рокицкая, Ю. А. (2017). Исследование мотивации профессиональной деятельности педагогов с различным уровнем эмоционального выгорания. Вестник Челябинского государственного педагогчческого университета, 1, 61-67.

Слепко, Ю. Н., Ледовская Т. В., Цымбалюк А. Э. (2018). Анализ данных и интерпретация результатов психологического исследования. Ярославль: РИО ЯГПУ.

Шадриков, В. Д. (2013). Психология деятельности человека. М.: Изд-во «Институт психологии РАН». Шадриков, В. Д. (2017). Системогенез деятельности. Игра. Учение. Труд (т. 1). М./Ярославль: Изд. дом РАО/ЯрГУ.

Ссылки на зарубежные источники см. в разделе References после англоязычного блока.

Горбушина Анастасия Владимировна - доцент, кафедра психологии, факультет педагогики и психологии, Педагогический институт, ФГБОУ ВО «Вятский государственный университет», кандидат психологических наук.

Сфера научных интересов: мотивация профессиональной деятельности.

Контакты: gorbushina_anast@mail.ru

Корчагина Галина Ивановна - доцент, кафедра психологии, факультет педагогики и психологии, Педагогический институт, ФГБОУ ВО «Вятский государственный университет», кандидат психологических наук, доцент.

Сфера научных интересов: системогенез профессионального развития личности.

Контакты: korchagina_g@mail.ru

\title{
Patterns of Changes in Teachers' Work Motivation
}

\author{
A.V. Gorbushina ${ }^{a}$, G.I. Korchagina ${ }^{a}$ \\ ${ }^{a}$ Vyatka State University, 36 Moskovskaya Str., Kirov, 610000, Russian Federation
}

\begin{abstract}
The relevance of the study lies in expanding scientific understanding of the emergence of changes and their patterns in teacher's work motivation, as well as in solving practical problems of supporting pedagogical activity by updating the resources of teachers' motivation. The purpose of the article is the description of the emergence of changes and their temporal patterns in teacher's work motivation based on the empirical study on the dynamics of the structure of motivation in teachers with different work experience. The methodological basis of the study is represented by the systemogenetic and metasystem approaches. The main research methods of the study are the analysis of psychological structures and the modeling method. As a result of their application, by comparing the systemogenetic patterns with changes in the structural-level organization of motivation in teachers, the emergence and the principles of transformation of teachers' work motivation in the time continuum were determined. The article reveals the predictors of the formation and patterns of the dynamics of subsystem and component levels in the
\end{abstract}


structure of teacher's work motivation. It is shown that at the first stages of the dynamics, changes in key levels of the structure are carried out according to the principles of systemogenesis: hierarchy, target determination, unevenness, differentiation, etc. After the system overcomes the crisis, changes are carried out according to the principles of metasystemogenesis: heterarchy, heterochronism, situational determination, cycles and others. The identification of temporal patterns of changes in the structure of motivation in teachers shows the non-linear nature of the transformation and the continuity of the development of motivation in the system of professional pedagogical activity. The data obtained can be used by specialists to design systems for updating the motivation and supporting the professional activities of teachers.

Keywords: conceptual model of teacher's work motivation, regularities of genesis, systemogenesis, principles of meta-systemogenesis.

\section{References}

Fernet, C., Trépanier, S.-G., Austin, S., \& Levesque-Côté, J. (2016). Committed, inspiring, and healthy teachers: How do school environment and motivational factors facilitate optimal functioning at career start? Teaching and Teacher Education, 59, 481-491.

Gorbushina, A. V. (2011). Struktura motivatsii professional'noi deyatel'nosti: metasistemnyi podkhod [The structure of motivation for professional activity: a metasystem approach]. Herald of Vyatka State University, 3(3), 138-141. (in Russian)

Gorbushina, A.V. (2018). Development of a system of motivation for professional activity in the context of pedagogical activity. Siberian Pedagogical Journal, 5, 83-95. doi:10.15293/18134718.1805 .09 (in Russian)

Kamalova, L. A., Korchagina, G. I., \& Bulatbaeva, K. N. (2016). Professional self-affirmation of a teacher as a functional activity system. International Electronic Journal of Mathematics Education, 11(1), 279-290.

Karpov, A. V. (2004). Metasistemnaya organizatsiya urovnevykh struktur psikhiki [Metasystem organization of level structures of the mind]. Moscow: Institute of Psychology of the RAS. (in Russian)

Karpov, A. V. (2015). Psikhologiya deyatel'nosti [Psychology of activity] (Vol. 3). Moscow: RAO. (in Russian)

Karpova, E. V. (2009). Struktura i genezis motivatsionnoi sfery lichnosti v uchebnoi deyatel'nosti [The structure and genesis of the motivational sphere of personality in educational activity] (DSc dissertation). Yaroslavl State University named after K. D. Ushinsky, Yaroslval, Russian Federation. (in Russian)

Kokurina, I. G. (1984). Sotsial'no-psikhologicheskie aspekty motivatsii trudovoi deyatel'nosti [Socio-psychological aspects of work motivation] (PhD dissertation). Lomonosov Moscow State University, Moscow, Russian Federation. (in Russian)

Kozhevina, A. P., \& Dubrovina, S. V. (2018). Professional motivation of comprehensive school teachers. Obshchestvo: Sotsiologiya, Psikhologiya, Pedagogika [Society: Sociology, Psychology, Pedagogy], 5, 39-45. (in Russian)

Levchenko, A. V. (2015). Osobennosti professional'noi motivatsii pedagogov [Specifics of professional motivation in teachers]. Kraevedenie Priamur'ya, 1(29), 23-27. (in Russian)

Lomov, B. F. (1984). Metodologicheskie i teoreticheskie problemy psikhologii [Methodological and theoretical problems of psychology]. Moscow: Nauka. (in Russian)

Lvova, S.V. (2015). The professional motivation of teachers of educational establishments. Sistemnaya Psikhologiya i Sotsiologiya [Systems Psychology and Sociology], 3, 54-62. (in Russian) 
Maruk, A. S., \& Pravdina, L. R. (2015). Features of motivation of srofessional activity of young teachers. Science Almanac, 10-4(12), 392-395. (in Russian)

Metelichev, V. V., \& Shingaev, S. M. (2014). Motivatsiya professional'noi deyatel'nosti i professional'noe vygoranie pedagogov: teoriya, diagnostika, vzaimosvyaz', profilaktika [Work motivation and professional burnout of teachers: theory, diagnostics, interconnection, prevention]. Saint Petersburg: $\mathrm{SPb}$ APPO. (in Russian)

Mintrop, R., \& Ordenes, M. (2017). Teachers work motivation in the era of extrinsic incentives: Performance goals and pro-social commitments in the service of equity. Education Policy Analysis Archives, 25(44), 1-15.

Petrash, E. A. (2017). Sotsial'naya identichnost'v norme i pri narushenii [Social identity in norm and its impairments] (DSc dissertation). Yaroslavl State University named after P. G. Demidov, Yaroslavl Russian Federation. (in Russian)

Ponomarev, I. P. (2004). Motivatsiya rabotoi v organizatsii [Motivation for work in organization]. Moscow: Editorial URSS. (in Russian)

Razina, T. V. (2016). Strukturno-funktsional'naya organizatsiya i genezis motvatsii nauchnoi deyatel'nosti [Structural and functional organization and the genesis of the motivation of scientific activity] (DSc dissertation). Yaroslavl State University named after P. G. Demidov, Yaroslavl, Russian Federation. (in Russian)

Rean, A. A. (1999). Psikhologiya izucheniya lichnosti [Psychology of the study of personality]. Saint Petersburg: Izdatel'stvo Mikhailova V.A. (in Russian)

Rokitskaya, Yu. A. (2017). Study of professional activity motivation of teachers with different levels of emotional burnout. Herald of Chelyabinsk State Pedagogical University, 1, 61-67. (in Russian)

Rozin, V. M. (2016). Views to the contemporary conception of development. Psychology. Journal of Higher School of Economics, 13(2), 367-385. (in Russian)

Shadrikov, V. D. (2013). Psikhologiya deyatel'nosti cheloveka [Psychology of human activity]. Moscow: Institute of Psychology of the RAS. (in Russian)

Shadrikov, V. D. (2017). Sistemogenez deyatel'nosti. Igra. Uchenie. Trud [Systemogenesis of activity. Game. Study. Work] (Vol. 1). Moscow/Yaroslavl: RAO Publishing House RAO/Yaroslavl State University. (in Russian)

Slepko, Yu. N., Ledovskaya, T. V., \& Tsymbalyuk, A. E. (2018). Analiz dannykh i interpretatsiya rezul'tatov psikhologicheskogo issledovaniya [Data analysis and interpretation of the results of psychological research]. Yaroslavl: RIO Yaroslavl State University. (in Russian)

Viseu, J., de Jesus, S. N., Rus, C., Canavarro, J. M., \& Pereira, J. (2016). Relationship between teacher motivation and organizational variables: A literature review. Paidéia, 26(63), 111-120. doi:10.1590/1982-43272663201613

Anastasia V. Gorbushina - Associate Professor, Department of Psychology, Faculty of Pedagogy and Psychology, Pedagogical Institute of Vyatka State University, PhD in Psychology. Research Area: professional motivation.

E-mail: gorbushina_anast@mail.ru

Korchagina Galina Ivanovna - Associate Professor, Department of Psychology, Pedagogical Institute of Vyatka State University, PhD in Psychology.

Research Area: systemogenesis of professional development of personality.

E-mail: korchagina_g@mail.ru 